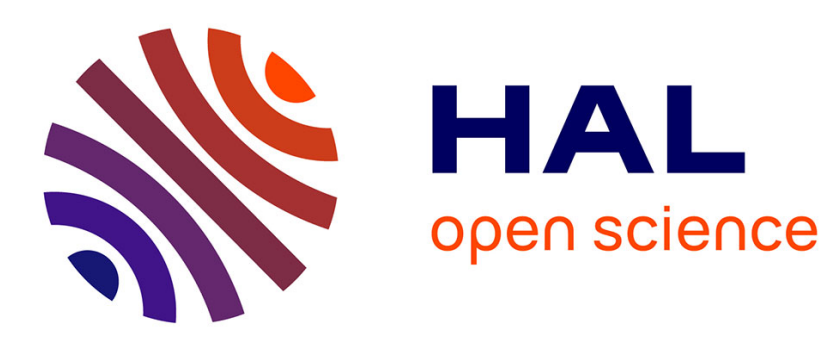

\title{
A detailed analysis of the productivity of solar home system in an Amazonian environment
}

Laurent Linguet, Isabelle Hidair-Krivsky

\section{To cite this version:}

Laurent Linguet, Isabelle Hidair-Krivsky. A detailed analysis of the productivity of solar home system in an Amazonian environment. Renewable and Sustainable Energy Reviews, 2010, 14 (2), pp.745-753. 10.1016/j.rser.2009.06.015 . hal-01304585

\section{HAL Id: hal-01304585 \\ https://hal.science/hal-01304585}

Submitted on 20 Apr 2016

HAL is a multi-disciplinary open access archive for the deposit and dissemination of scientific research documents, whether they are published or not. The documents may come from teaching and research institutions in France or abroad, or from public or private research centers.
L'archive ouverte pluridisciplinaire HAL, est destinée au dépôt et à la diffusion de documents scientifiques de niveau recherche, publiés ou non, émanant des établissements d'enseignement et de recherche français ou étrangers, des laboratoires publics ou privés. 


\title{
A Detailed Analysis of the Productivity of solar home system in an Amazonian Environment
}

\author{
L. LINGUET ${ }^{\text {a }}$, I. HIDAIR ${ }^{\text {b }}$ \\ ${ }^{a}$ Research Group on Renewable Energies (GRER), University of the French Antilles and French Guiana's, \\ Campus Saint-Denis, Avenue d'Estrées, 97337 Cayenne Cedex, France \\ b anthropologue, University of the French Antilles and French Guiana's, Campus Saint-Denis, Avenue d'Estrées, \\ 97337 Cayenne Cedex, France
}

\begin{abstract}
.
This papers studies the productivity of solar home systems in French Guiana, a region characterized by specific human and environmental conditions.

Its aim was a better understanding of the attitudes, expectations, and relationship of the users towards the solar home system. The data collected made it possible to make suggestions for adapting the photovoltaic systems to their environment by taking into account social, cultural, and geoclimatic specificities. Analysis of on-site productivity provides valuable information on energy profiles and types of use. Field surveys made it possible to associate users' perception of the energy production equipment and their degree of satisfaction with operating efficiency and on-site maintenance. This aspect is essential for analyzing the actual rate of use of the energy that is theoretically available.

Parallel to these surveys, the results of the study carried out on the performance of the photovoltaic systems made it possible to learn the quantitative aspects of the energy produced and consumed as well as the qualitative aspects of the parameters that condition the performance of the photovoltaic systems.

After keyboarding, the subjective, qualitative as well as the quantitative variables were processed using a statistical analysis program in order to determine the correlations between them and to prepare the final conclusions. These surveys and measurements were carried out simultaneously over the 2004-2006 period.
\end{abstract}

Keywords : Rural photovoltaic electrification, Solar home system, French Guiana 


\section{Introduction}

It is widely accepted today that technological progress cannot be pursued as an end in itself, without taking into account its impact on users. Scientific efforts are expected to have a true impact on the comfort of individuals, improvement of the economy, and how societies function. The study presented in this article deals with the issue of photovoltaics (PV) in French Guiana, considered as a technique imported into a region characterized by specific human and environmental conditions. Granted, the issue of «classic photovoltaics» has been studied extensively. The notion of "classic photovoltaics" refers to:

- the implementation of the technical system under optimal operating conditions (that is, in a temperate climate or in the laboratory)

- adaptation of the technical system for a Western, urban, or semi-urban public.

However, there are several fundamental reasons why it can be said that photovoltaic systems are not suitably adapted to living and operating conditions encountered in French Guiana:

Environmental conditions are not always favorable:

- A long rainy season during which solar radiation is low (6 months/year)

- High humidity, which promotes the growth of moss on the panels

- High humidity, which promotes battery discharge

Specific social and geographical conditions characterized by :

- The presence of non-homogenous populations stemming from various cultures

- The presence of isolated villages and municipalities which are difficult to reach (no road access, access only possible by river or helicopter

It must be noted that in a real-life situation, the notion of reliability no longer covers only those parameters recognized in the laboratory. Other parameters linked to user perception and operating conditions have to be taken into account. The concept of reliability covers not only certainty of correct performance but also overall productivity and includes the human factor. This distinction is particularly important for photovoltaic installations located in isolated areas. It is therefore necessary to conduct a study on the habits and expectations of the populations, taking sociocultural parameters into account.

One aspect of this work studies the operating characteristics of the photovoltaics systems currently installed in French Guiana. The aim is to define the average productivity of these photovoltaics systems compared to production rates announced by the manufacturer. A series of measurements was taken on photovoltaics systems installed at pre-selected sites. These measurements provide quantitative and statistical data on the operating conditions of the 
modules, as well as data concerning the characteristics linked to the quantities of energy produced and the quantities of energy consumed.

We identified:

- the quantity of energy produced by each photovoltaic system

- the quantity of energy consumed by each home

- failures of photovoltaic modules

- complete discharges of batteries

- maximum solar radiation levels

Correlations were established between:

- solar radiation and the quantity of energy produced

- the quantity of energy produced and the quantity of energy consumed

- $\quad$ solar radiation and the quantity of energy consumed

Analysis of these measurements provides:

- an evaluation of average operating conditions for the modules

- consumption rates of produced energy

- the ratio between measured $\mathrm{kWh}$ and $\mathrm{kWp}$ announced by the manufacturer

The second aspect of this work introduces questions about the use of solar home equipment by populations whose culture differs from Western culture. The cultural differences of the societies in which this equipment was set up make it impossible to transpose identical energy use inspired by the Western model. In addition, access conditions, demands, and practices diverge according to cultural affiliation and place of residence. Although introducing solar home systems enables the vast majority of these populations to benefit from access to electrical energy, a thorough understanding of its effects is necessary in order to increase its chances of being efficient. In order to understand the complex situation created by introducing new technologies into non-westernized or minimally westernized societies, the following elements should be studied: the perception of energy among these populations, the overall perception of the system or technology introduced, the degree of acceptation of its constraints, and the impact on the economic, social, and cultural aspects of their way of life. Socio-anthropological surveys were conducted at several sites equipped with individual photovoltaic units spread throughout French Guiana. These surveys made it possible to associate users' perception of the energy production equipment with their degree of satisfaction with operating efficiency and on-site maintenance. This aspect is decisive and will be compared with the actual rate of use of the energy that is theoretically available. These socio-anthropological surveys were carried out by meeting with several categories of users. Besides their cultural affiliation and their place of residence, other parameters were also taken into account, such as: age, socio-professional category, marital status, income, household composition, practices linked to use of household appliances, and acculturation phenomena caused by introducing a technical progress previously unknown to certain populations. We 


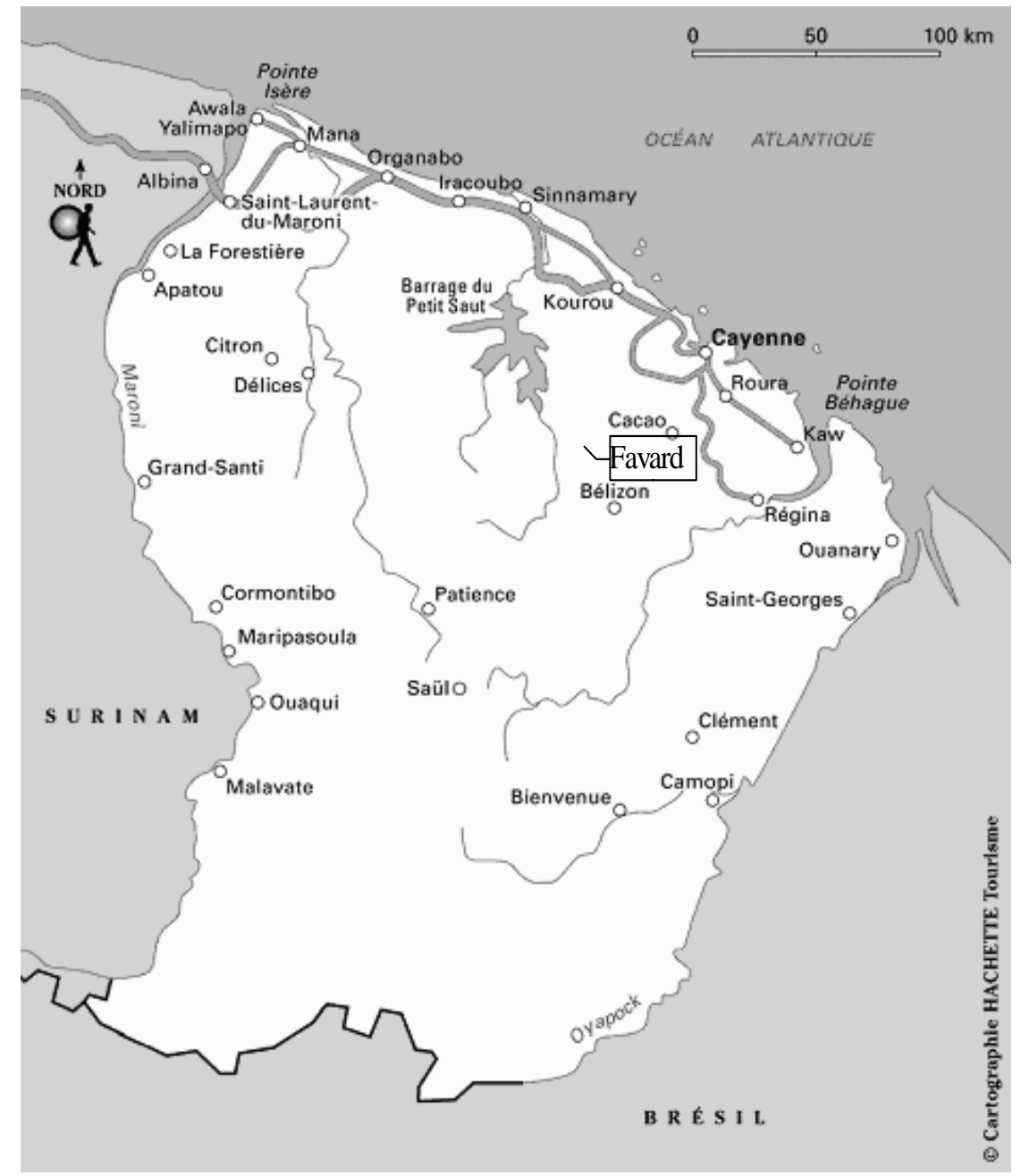

Fig.1. Selection of sampling and measurement sites

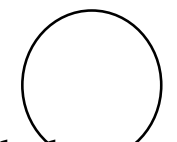

will also-attempt to answer the following questions: Which aspects of the technology were best accepted? Which factors may incite users to cooperate or on the contrary reject the system? What would be the impact of a more or less significant implication of the users in the running of the system? What types of maintenance activities would be most adapted? What type of training should be planned for?

Definition of the sampling and measurement sites was carried out in coordination with the locally-based companies that installed the photovoltaics systems. Sites were chosen according to two criteria:

(i) Carry out measurements in several different areas that are geographically isolated and/or hard to reach spread over the entire territory of French Guiana

(ii) Favor sites witch residents have different cultural affiliation

The areas selected and shown on the Figure 1. are :

- Municipality of Roura (creole and metropolitan french residents) 
- Municipality of Saül (creole residents)

- Maroon villages of Maroni Valley-Apatou (maron residents)

- Municipality of Saint Laurent and Mana (creole and metropolitan french residents)

- The Amerindian village of Favard (amerindian residents)

\section{Socio-anthropological surveys results}

\section{Municipality of Roura}

Study surveyors visited twenty-three homes equipped with photovoltaic systems scattered over various areas in the municipality of Roura. The homes are located far from the main village of the municipality in areas not reached by EDF's electrical grid. Nevertheless, these homes are easily reachable by dirt roads suitable for vehicles which branch off from a national or departmental road. They are therefore only relatively isolated.

The persons surveyed were heads of households, RMI (guaranteed minimum income) recipients, and resided in the Roura area (mainly French Guianese Creoles and Metropolitan French). The majority of them had regular incomes of between $500 €$ and $999 €$. These were mainly families composed of three children under 15 and three adults (15 and over). Most of the people interviewed had benefited from the installation for 3-4 years. Inside the houses, the main electrical appliances were televisions (91\%), refrigerators (65\%), and stereo systems $(47 \%)$. We also observed that many had video recorders, microwave ovens, computers, and satellite television service. Daily use of the television is significant. It is the main entertainment and "standby" mode seems to be the first choice of the people questioned when they are not watching. Indeed, the television was mentioned first among appliances that are always on. A broad majority of users are satisfied with solar energy which they find "useful," "indispensable for all" and ecological, but a broad majority regretted the fact that the system functions poorly in rainy weather. $60 \%$ are not prepared to break their contract with the company that installed the photovoltaic system as they are satisfied with the service, but certain users would prefer a type of installation that would provide more constant production and have fewer constraints. Being dependent on weather conditions and having to maintain the installations and manage energy consumption appear to detract from the image of the photovoltaic system.

\section{$\underline{\text { Municipality of Saül }}$}

The village of Saül is located in the middle of French Guiana, in the heart of the forest, cut off from any road or river access. The village can only be reached by air, a trip that takes approximately one hour from Cayenne, the capital. The village is equipped with autonomous solar generators in order to satisfy the energy needs of the inhabitants. Twenty-three users of photovoltaic systems were questioned. The majority of the persons questioned were men $(68.42 \%)$, heads of households, and RMI recipients. They were mainly French Guianese Creoles (57.89\%) and Metropolitan French (31.58\%). 36.84\% of them had regular incomes of 


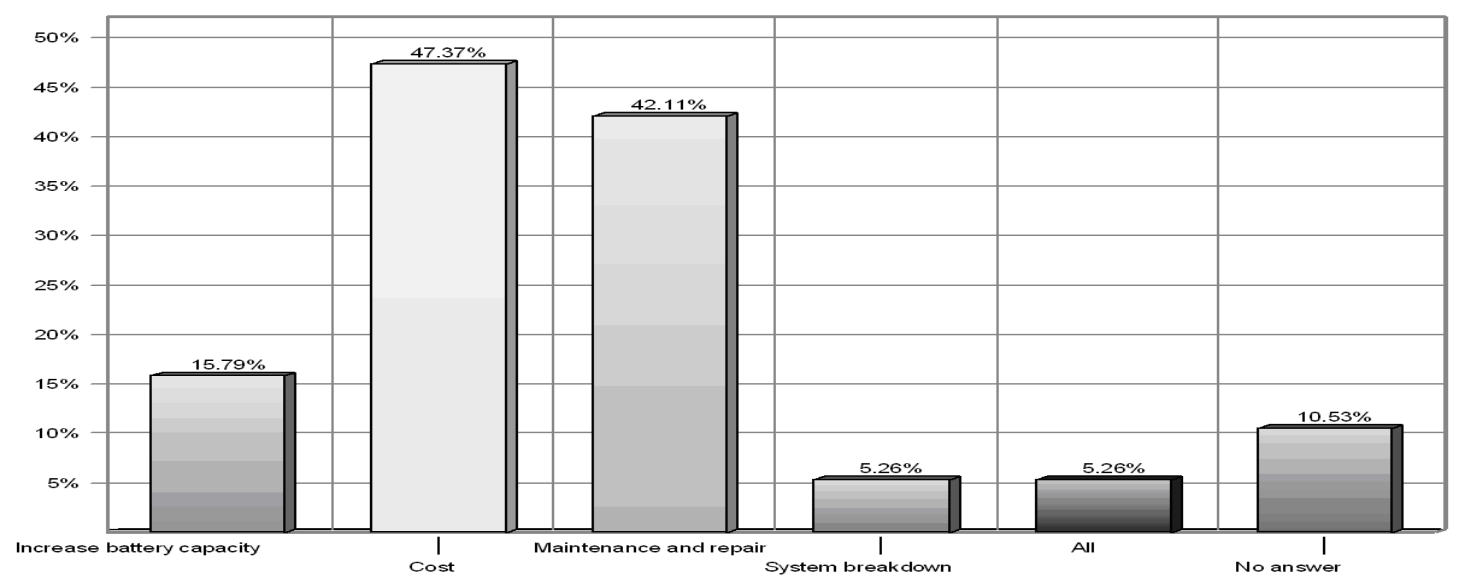

Fig. 2.(Saül) Answers to the question: What are the drawbacks of the photovoltaic system ?

between $250 €$ and $499 €$. The people questioned were mainly couples without children. Most of the people interviewed had benefited from the installation for 2 years. Inside the houses, the main appliances were electric refrigerators (100\%), freezers (94.74\%), stereo systems (63.16\%), and televisions (21\%). A broad majority of the users are satisfied that they can keep their food refrigerated. But a broad majority of them regretted the high cost and the maintenance and repairs required by the system. Client perception of the company that installed the PV systems can be summed up as follows:

- $46.67 \%$ of the clients are satisfied and acknowledge "having no problem" with the company

- $33.9 \%$ of the clients, who could be termed "indifferent", are not concerned by the image transmitted by the company.

- $13.34 \%$ of the clients are dissatisfied and accuse the company of not repairing system failures.

Half of those questioned consider that they do not have a satisfactory relationship with the installation company and deplore the fact that they are not completely satisfied with the photovoltaic system. A high proportion of the users questioned also complained about the cost, which they considered high. Many clients used a generator before the introduction of solar energy. They acknowledge the improvement in family living conditions since the change to solar energy and the fact that the system is more economical and quieter than using a generator. But they admitted that, if they no longer had electricity, they would use gas and would go back to living "like they did before." Electricity is considered indispensable $(38.84 \%)$ but the percentage of people without an opinion is identical. 


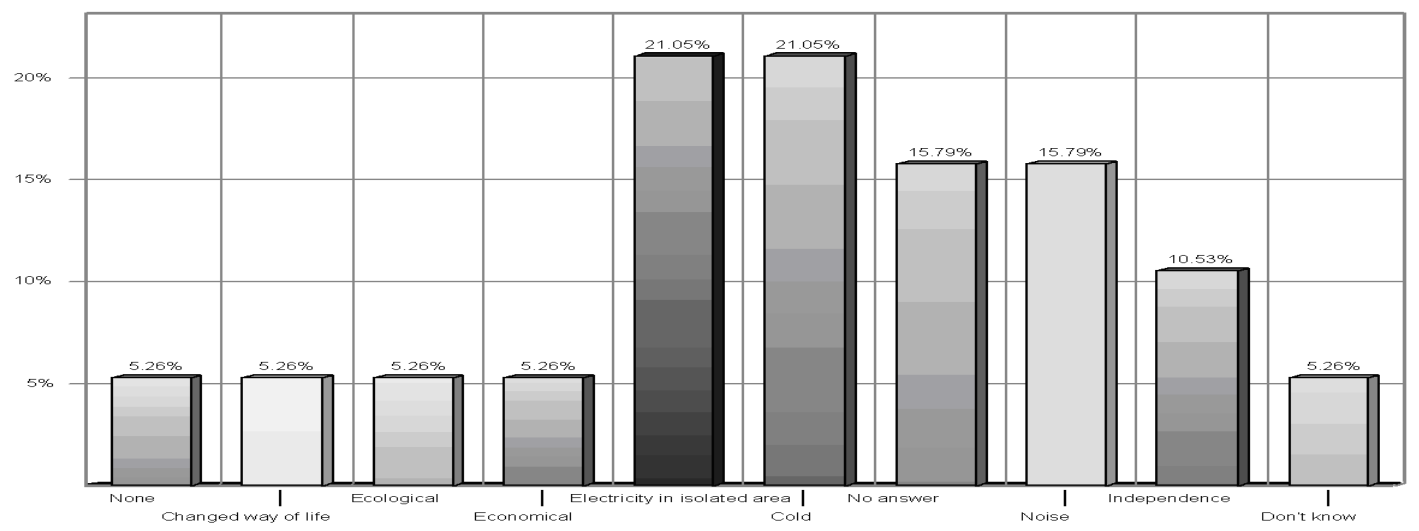

Fig. 3.(Saïl) Answers to the question : What are the advantages of the photovoltaic system?

\section{Municipality of Mana and Saint-Laurent}

The homes visited for the survey were located away from the main villages (Mana and Saint Laurent), off the EDF electricity grid, but easily reachable by car by following dirt tracks branching off of the main roads for a few minutes. The EDF electricity grid runs alongside the main roads. Men and women were equally represented (50\% each) among the persons questioned. The most highly represented cultural group (80\%) were the Metropolitan French. Half of the people surveyed were teachers and the average monthly income of the clients who answered the question was between $1000 €$ and $1499 €(62.5 \%) .100 \%$ of these incomes were monthly. $25 \%$ of the clients had had access to solar energy for 4 years and $25 \%$ for 7 years. $62.5 \%$ of the persons questioned are satisfied with solar energy, which they describe as ecological and natural. The following drawbacks were mentioned: The low capacity of the batteries (37.5\%), insufficient energy during rainy weather. Concerning the changes in their life since the system was installed: $25 \%$ think that "it's good": life is easier, safer, more comfortable; they highlighted the possibility of having appliances and the economic aspect. However, the same proportion (25\%) gave no answer.

The appliances owned were stereo systems (100\%), refrigerators (100\%), televisions $(62.5 \%)$, and computers (62.5\%). 75\% consider electricity "indispensable" and 62.5\% are not prepared to break their contract. $62.5 \%$ consider their relationship with the installation company to be "satisfactory" and 50\% claim to have no problem.

Having electricity has:

- led to new evening activities (25\%)

- enabled the use of new tools $(12.5 \%)$

- created new activities within the family (12.5\%) 
The majority of clients at this site were of European origin and had fairly high incomes (the highest of all the clients in the study). They were all located close to roads and were isolated mainly in terms of access to the electricity grid.

\section{Maroon villages of Maroni Valley - Apatou}

The photovoltaic installations and homes visited are located on the banks of the border river, the Maroni. They can only be reached by river; the trip from Saint Laurent takes two hours. The homes visited were located in several villages scattered along the river, which constitutes the sole transportation route between them: Spawine, Patience, Petit Patience, Anaoulaondo, and New-Campo. The EDF electricity grid stops at Saint Laurent and is not extended along the Maroni river up to a point near these living places. Twenty-five clients who use the photovoltaic systems were questioned.

All of the users and persons questioned belonged to the Maroon cultural group. Women were broadly represented $(72 \%)$. The main sources of income were the RMI $(44 \%)$ and child benefits $(44 \%)$. The persons questioned stated that they had incomes under $249 €$ per month (44\%) ; it should be pointed out that $56 \%$ did not answer that question.

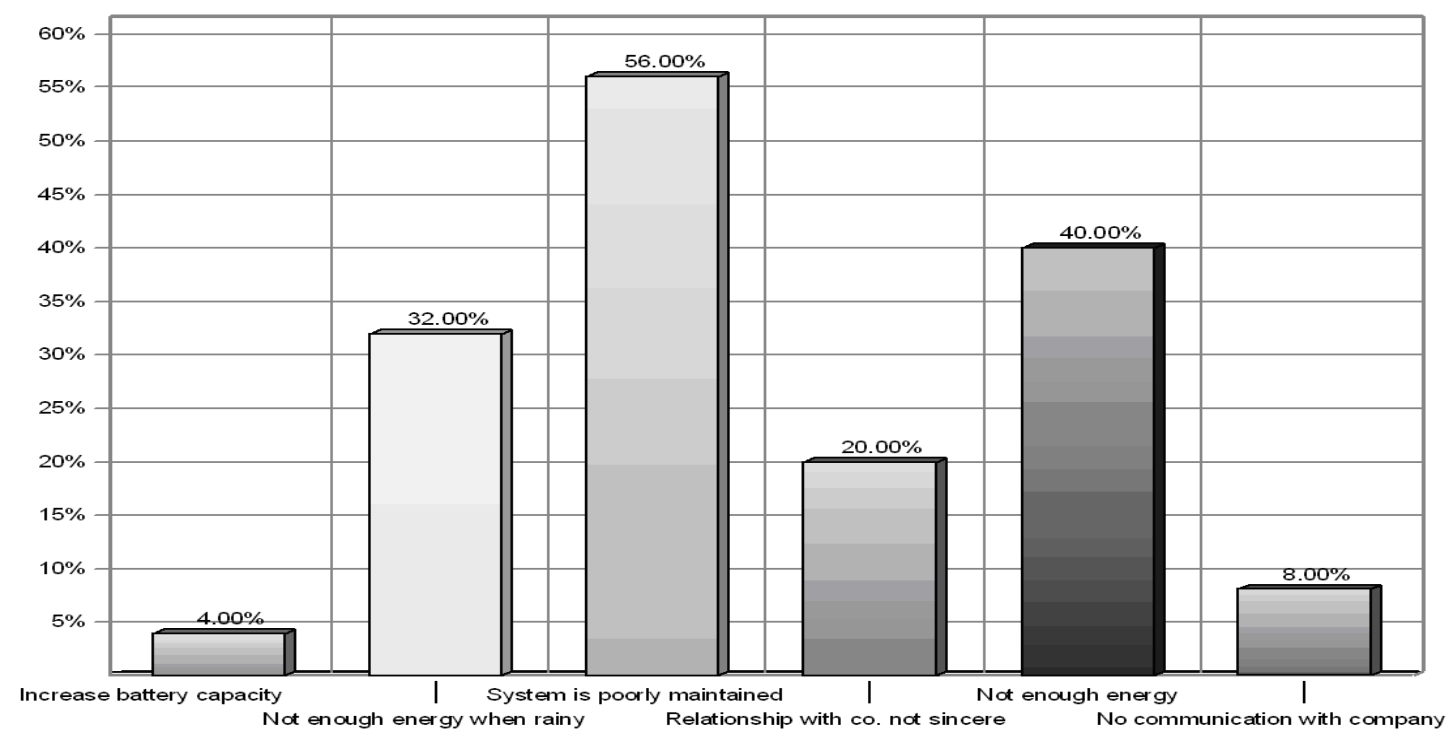

Fig. 4.(Apatou) What are the drawbacks of solar home system? (What should be changed?)

$36 \%$ of the clients had had access to solar energy for 7 years.

Certain advantages were acknowledged, namely :

- the quietness of the system compared to generators (48\%)

- the possibility of using electricity day and night (24\%)

- the possibility of benefiting from electricity in an isolated area (24\%) 
The drawbacks highlighted were :

- poor maintenance of the system $(56 \%)$

- low capacity of the batteries (40\%)

- power failures during rainy weather $(32 \%)$

- lack of sincerity between them and the installation company (20\%).

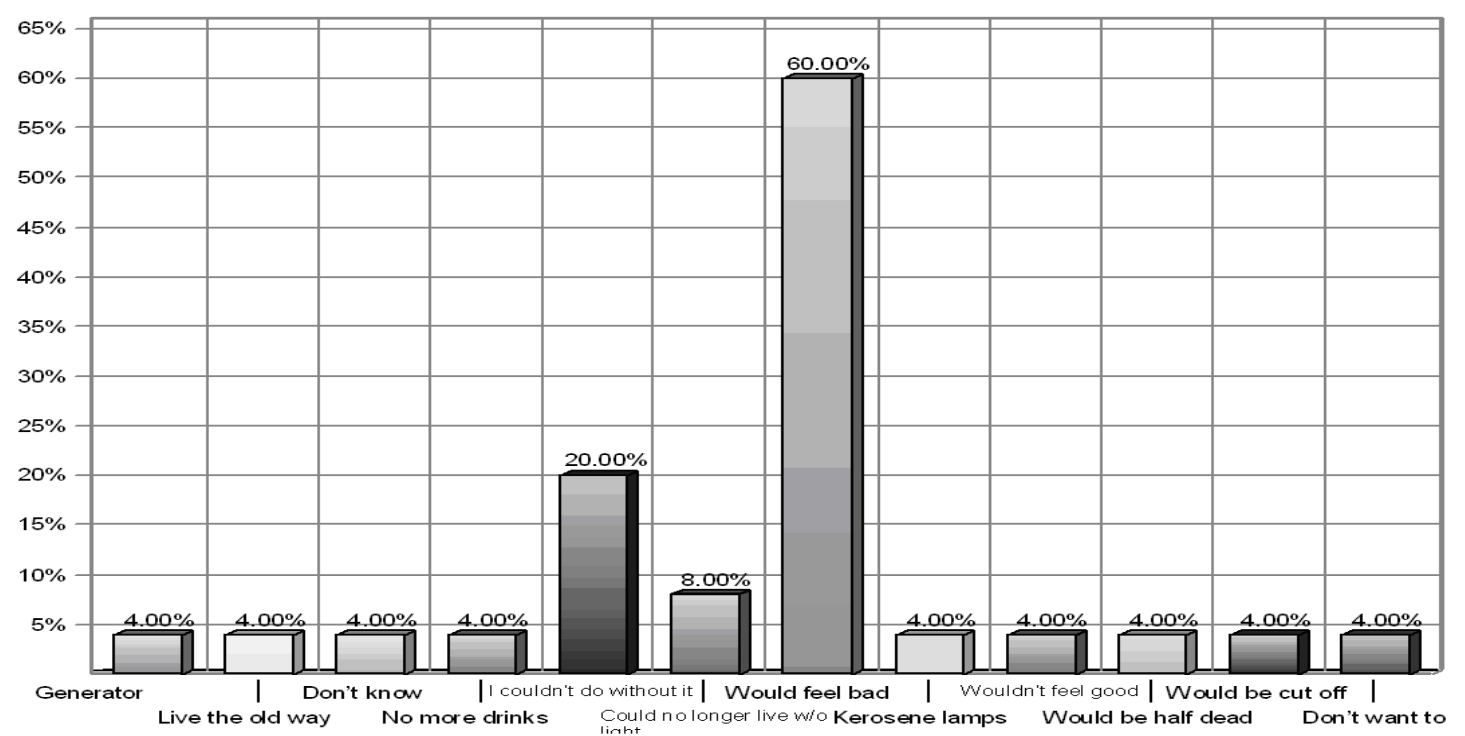

Fig. 5.(Apatou) Explain what it would be like if you no longer had electricity?

$88 \%$ of the users admitted to not having understood the agreements signed with the installation company and $84 \%$ described their relationship with the latter as " not at all satisfactory". The main reasons stated were the lack of maintenance and follow-up $(29.17 \%)$, the company's lax attitude $(16.67 \%$,), and the lack of visits to check installations $(16.67 \%)$. A majority of the clients $(64 \%)$ are not satisfied with solar energy. The main reasons mentioned were maintenance of the system (32\%); others thought that this represented a defect $(20 \%)$. Before the system was installed, $28 \%$ of users used kerosene lamps and $24 \%$ a generator. Since the system was installed, they acknowledge the following changes:

- the advantage of having light at night (25\%)

- the possibility of refrigerating food $(16.67 \%)$

- the possibility of having more leisure activities (16.67\%)

$60 \%$ admitted that they would feel "bad" if they didn't have electricity. Thus, $88 \%$ would not be prepared to break their contract. However, among those who would, $66 \%$ admitted that they would be motivated by the fact that the system breaks down and has defects.

The appliances owned are as follows, by order of importance:

- televisions (69.57\%), freezers (65.22\%), stereo systems $(56.52 \%)$ 


\section{Amerindian village of Favard}

The Amerindian village of Favard is located in the municipality of Roura, on the right bank of the Oyack river, fifteen minutes by canoe from the village of Roura. It can be reached by taking a road (which is in very bad condition due to the rains) that goes through the forest; the trip from Roura takes less than an hour. The EDF electricity grid does not pass near the road. All twelve clients who use the photovoltaic systems in the village were questioned. All the users and inhabitants of this village belong to the Amerindian cultural group. $41.67 \%$ of the people surveyed were between 25 and 29 years of age and $75 \%$ were men. $60 \%$ of the clients questioned are employed, 50\% are RMI recipients, and $16.67 \%$ are farmers. Their average monthly income $(45.45 \%)$ is between $250 €$ and $499 €$. 50\% have had access to solar energy for 6 years. Electricity was described as indispensable by $91.67 \%$ of the clients. If they no longer had electricity, $41.67 \%$ would go back to the old ways and $25 \%$ would look for another way to satisfy their energy needs. A considerable proportion of the clients (66.67\%) claim to be satisfied with the presence of the photovoltaic system. The advantages stated were having electricity in an isolated zone (58.33\%) and the ecological aspect (16.67\%).

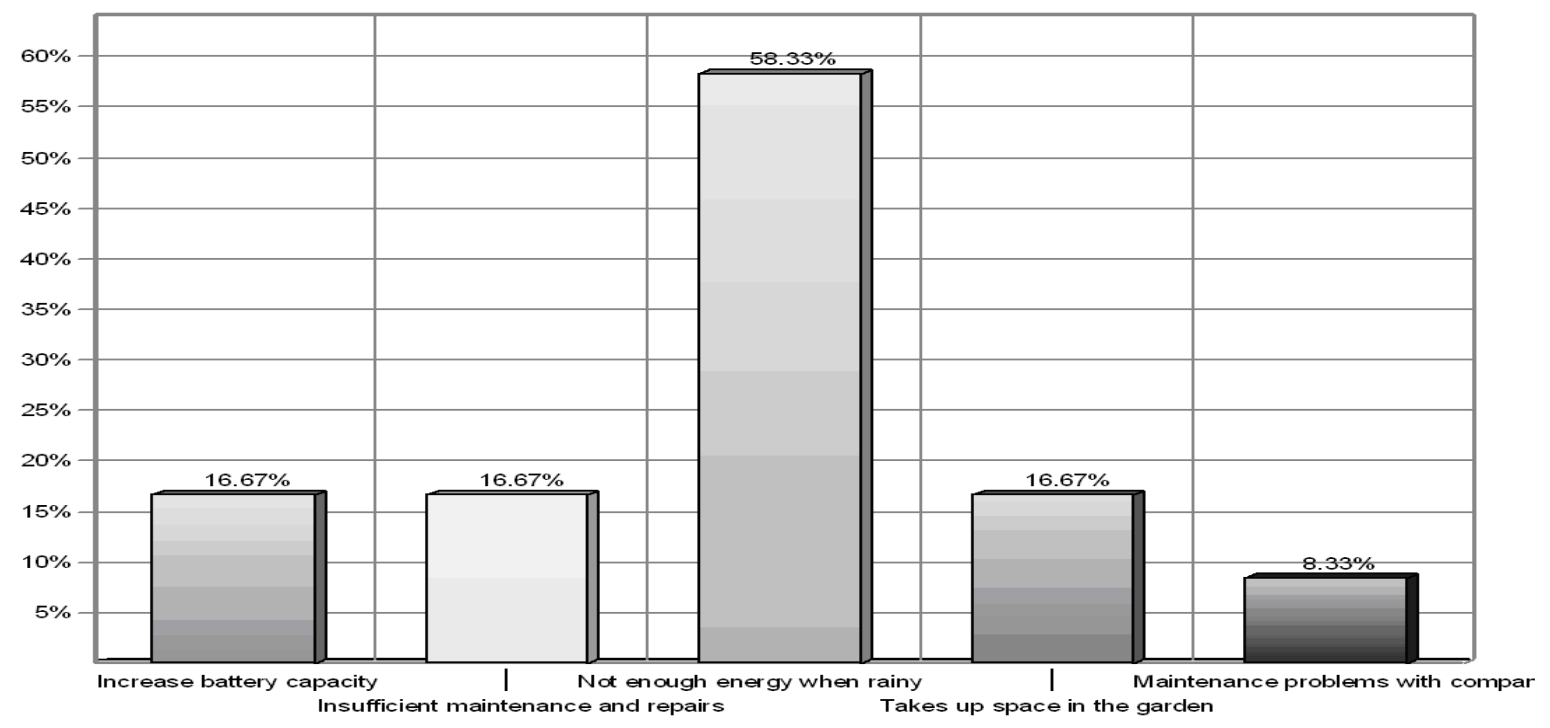

Fig. 6. (Favard) What are the drawbacks of solar home system?

Nevertheless, the clients appeared to be dissatisfied with the performance of the system. The main drawbacks noted by the clients were:

- that there is "not enough energy in rainy weather" $(58,33 \%)$

- that maintenance and repair are insufficient (16.67\%)

- that battery capacity is low (16.67\%)

- that the installation takes up room in the garden (16.67\%). 
$33.33 \%$ described the nature of their relationship with the company as "not at all satisfactory" and $25 \%$ considered it to be "satisfactory". However, $16.67 \%$ did not answer and $33.33 \%$ don't know. How should this "heavy" silence be interpreted?

Concerning the reasons for this opinion, of the total number of persons questioned:

- $16.67 \%$ accused the company of carrying out " insufficient maintenance"

- $8.33 \%$ think that there are "a lot of mistakes"

- $8.33 \%$ wonder how the company regards them

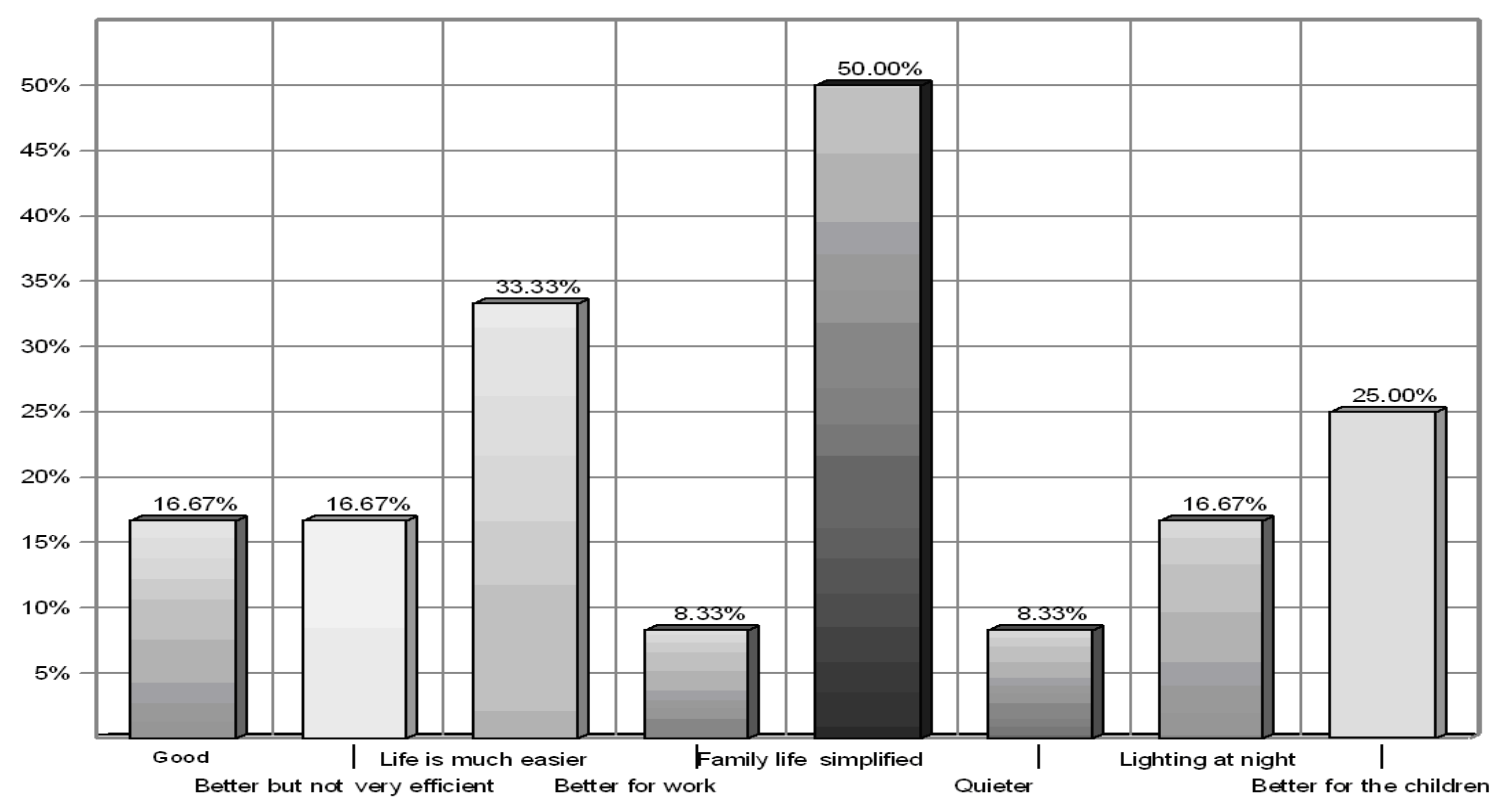

Fig. 7. (Favard)What has changed in your life since the system was installed?

$50 \%$ of the clients stated that they did not understand the agreements signed with the installation company. We should emphasize the fact that $66.67 \%$ are not prepared to break their contract with the installation company for several reasons : They have no problem for the moment $(62.50 \%)$ and think that they would have "more problems afterwards" $(25 \%)$ if they didn't have access to electrical energy. However, $25 \%$ of the clients would agree to do without it, and $33.33 \%$ would do it "if there were a new solution" that would replace the solar energy. The appliances owned were :

- refrigerators $(83.33 \%)$, gas cooking stoves $(58.33 \%)$, stereo systems $(25 \%)$

The main change mentioned by the clients was the simplification of family life (50\%). They specified that "life is much easier" (33.33\%) and better for the children (25\%).

$91 \%$ stated that there were people at home all day long. These were mainly members of the family. These people do the housekeeping and, during the day, energy is also used to watch television and listen to the radio. Most of the clients in this residential area are not satisfied with the services of the installation company. System failures (due to the weather, 
breakdowns), combined with incorrect use of electrical appliances by the clients, exacerbate this dissatisfaction.

\section{PV Performance Results}

The numerous performance data recorded by the PV systems' calculators were integrated into a calculation program (Excel) which made it possible to extract the average values per site. Useful variables for our study are presented in table 1 . We observed that the energy potential captured by the solar panels and recorded by the installations' data logging systems (SUNPAC or ENERPEC) varies considerably from one site to another. There is a $20 \%$ gap between the highest energy potential and the lowest. The measurements of the average energy consumption of users at each site during the first two years of PV system operation reveal significant differences that cannot be explained by the variation in potential solar energy alone. There is a $50 \%$ gap between extreme consumption levels. The lowest consumption levels were found in Saül and Favard.

Table 1 :Average Daily and Annual Values Drawn from the Data Recorded on the PV Systems for the first two years following commissioning of PV systems

\begin{tabular}{|c|c|c|c|c|c|c|c|}
\hline $\begin{array}{l}\text { IDENTI- } \\
\text { FIED } \\
\text { VALUES }\end{array}$ & $\begin{array}{l}\text { Potential } \\
\text { energy of solar } \\
\text { panels or } \\
\text { average } \\
\text { theoretical } \\
\text { producible } \\
\text { solar energy } \\
\text { per day }\end{array}$ & $\begin{array}{c}\text { Average } \\
\text { actual solar } \\
\text { energy } \\
\text { supplied } \\
\text { per day }\end{array}$ & $\begin{array}{c}\text { Daily } \\
\text { consumpti } \\
\text { on profile }\end{array}$ & $\begin{array}{c}\text { Average } \\
\text { consumption } \\
\text { rate of average } \\
\text { actual solar } \\
\text { energy } \\
\text { supplied }\end{array}$ & $\begin{array}{c}\text { Average } \\
\text { consumption } \\
\text { rate of } \\
\text { average } \\
\text { producible } \\
\text { energy }\end{array}$ & $\begin{array}{c}\text { Estimated } \\
\text { proportion } \\
\text { of defects } \\
\text { in the } \\
\text { battery } \\
\text { bank }\end{array}$ & $\begin{array}{c}\text { Average } \\
\text { maximum } \\
\text { current } \\
\text { during the } \\
1^{\text {st year }(A)}\end{array}$ \\
\hline APATOU & $3.3 \mathrm{kWh}$ & $3.18 \mathrm{kWh}$ & $2.7 \mathrm{kWh}$ & $85 \%$ & $82 \%$ & $45 \%$ & 28.6 \\
\hline FAVARD & $2.83 \mathrm{kWh}$ & $2.1 \mathrm{kWh}$ & $1.29 \mathrm{kWh}$ & $62 \%$ & $45.5 \%$ & $57 \%$ & 19.6 \\
\hline $\begin{array}{l}\text { St.LAURENT } \\
\text { and MANA }\end{array}$ & $3.3 \mathrm{kWh}$ & $3.24 \mathrm{kWh}$ & $2.25 \mathrm{kWh}$ & $69 \%$ & $68 \%$ & $5 \%$ & 38.7 \\
\hline ROURA & $3 \mathrm{kWh}$ & $2.8 \mathrm{kWh}$ & $2.3 \mathrm{kWh}$ & $83 \%$ & $77 \%$ & $5 \%$ & \\
\hline SAUL & $2.64 \mathrm{kWh}$ & $1.9 \mathrm{kWh}$ & $1.3 \mathrm{kWh}$ & $70 \%$ & $50 \%$ & $0 \%$ & \\
\hline
\end{tabular}

The following table 2 mentions the measurements of the actuals average energy consumption of users at each site, table 2 highlights the rapid deterioration of proper PV system performance, particularly at the sites inhabited by Amerindian (Favard) and Maroon (Apatou) populations. The gap between the highest energy level and the lowest increases to $40 \%$ when we evaluate the energy actually captured. These high defect rates are mainly due to insufficient battery maintenance and repair, both by clients and by the installation company 
Table 2 : Actuals average Daily and Annual Values Drawn from the Data Recorded on the PV Systems

\begin{tabular}{|l|l|l|l|l|l|l|}
\hline $\begin{array}{c}\text { IDENTI-FIED } \\
\text { VALUES }\end{array}$ & $\begin{array}{c}\text { Potential } \\
\text { energy of solar } \\
\text { panels or } \\
\text { average } \\
\text { theoretical } \\
\text { producible } \\
\text { solar energy } \\
\text { per day }\end{array}$ & $\begin{array}{c}\text { Average } \\
\text { actual solar } \\
\text { energy } \\
\text { supplied per } \\
\text { day }\end{array}$ & $\begin{array}{c}\text { Daily } \\
\text { consumption } \\
\text { profile }\end{array}$ & $\begin{array}{c}\text { Average } \\
\text { consumption } \\
\text { rate of average } \\
\text { actual solar } \\
\text { energy } \\
\text { supplied }\end{array}$ & $\begin{array}{c}\text { Average } \\
\text { consumption } \\
\text { rate of average } \\
\text { producible } \\
\text { energy }\end{array}$ & $\begin{array}{c}\text { Estimated } \\
\text { proportion of } \\
\text { defects in the } \\
\text { battery bank }\end{array}$ \\
\hline APATOU & $3.3 \mathrm{kWh}$ & $3.18 \mathrm{kWh}$ & $1 \mathrm{kWh}$ & $30 \%$ & $31.4 \%$ & $80 \%$ \\
\hline FAVARD & $2.83 \mathrm{kWh}$ & $2.1 \mathrm{kWh}$ & $0.6 \mathrm{kWh}$ & $21 \%$ & $29 \%$ & $80 \%$ \\
\hline $\begin{array}{l}\text { St-LAURENT } \\
\text { et MANA }\end{array}$ & $3.3 \mathrm{kWh}$ & $3.24 \mathrm{kWh}$ & $2.25 \mathrm{kWh}$ & $69 \%$ & $68 \%$ & $5 \%$ \\
\hline ROURA & $3 \mathrm{kWh}$ & $2.8 \mathrm{kWh}$ & $2.3 \mathrm{kWh}$ & $83 \%$ & $77 \%$ & $5 \%$ \\
\hline SAUL & $2.64 \mathrm{kWh}$ & $1.9 \mathrm{kWh}$ & $1.3 \mathrm{kWh}$ & $70 \%$ & $50 \%$ & $0 \%$ \\
\hline
\end{tabular}

The defect rates recorded at the more accessible sites of Mana and St. Laurent were lower, as clients of Metropolitan French origin played a greater role in battery inspection and maintenance, which made it possible to keep the installation in good working order.

\section{Discussion}

The study shows that the issue of energy in truly isolated areas is considered vital by the populations who live in these areas and who do not have other similar-strength energy sources available to them (Apatou, Favard). We observed in Figure 8. that the users belonging to the Amerindian and Maroon communities who have access to electrical energy and currently have the lowest consumption rates are also the most numerous in percentage terms to consider it indispensable.

The downward trend over the past few years of consumption levels of solar energy actually supplied to the system at the Apatou and Favard sites has not had a negative impact on user perception concerning electrical energy. On the other hand, the Saül site shows low adherence to the need for solar-derived electrical energy even though the clients' battery bank is in good condition, but its solar potential is lower than all the other sites. Strangely, when we examined the possible correlation between the users' interest in solar-derived electricity and the solar potential of the site (Fig.8.) we discovered that these data were proportional: the lower the solar potential, the weaker the users' interest in solar energy. This was particularly true for Saül.

The study point out that introducing new technologies into populations with different socio-cultural backgrounds produces specific responses. The following examples will illustrate our statements: 


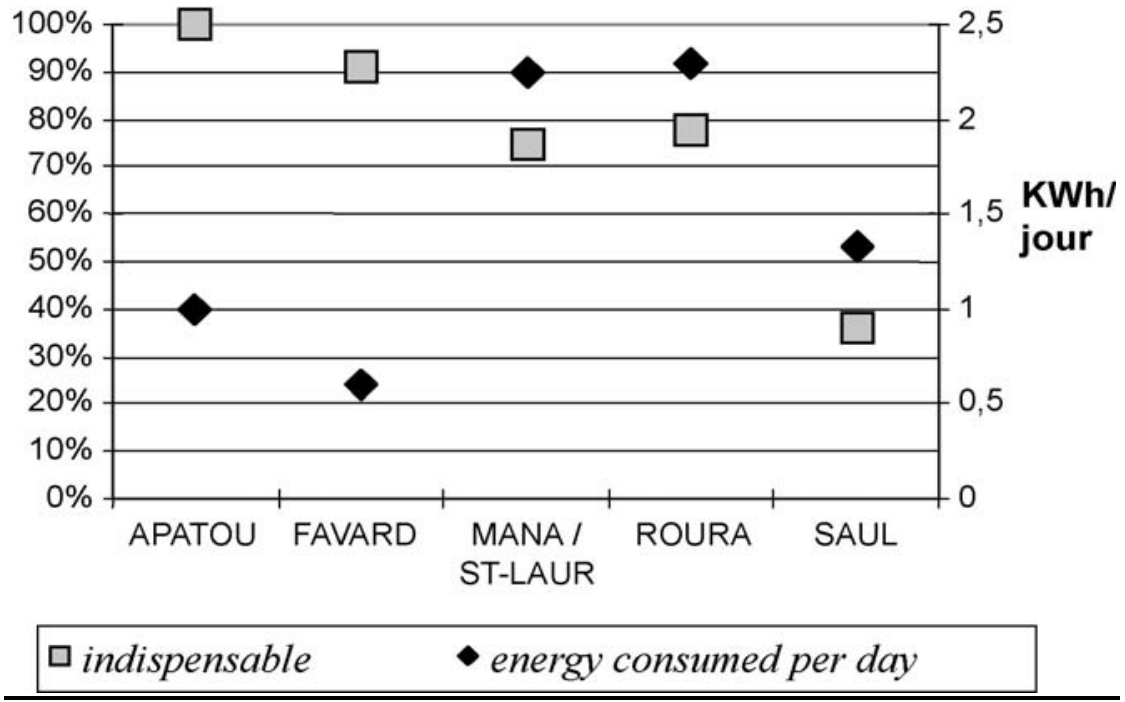

Fig. 8. A Correlation between user perception of PV electrical energy and energy consumed per day

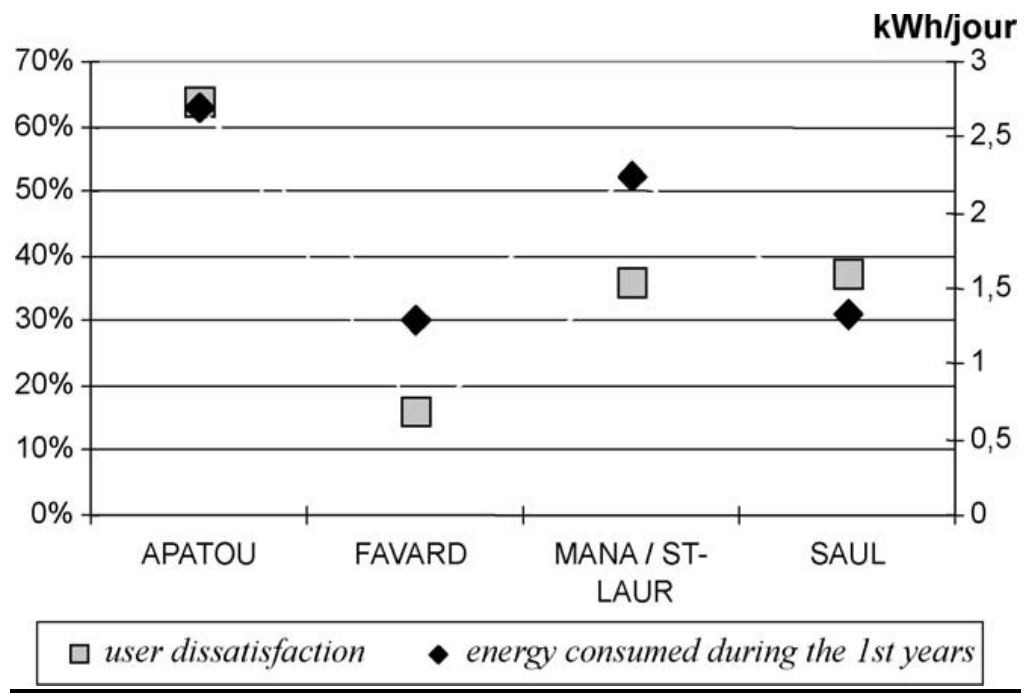

Fig. 9. Correlation between users dissatisfaction and energy consumed during the first 2 years.

- At the Saül site, we observed that the insufficiency of potential energy available seemed to be at the root of a marked deterioration of solar installation performance. The discrepancy between announced and actual performance and the desire of the installers to maintain this type of production system in spite of poor performance appears to have produced an attitude of rejection of the technology among the population of Saül, composed mainly of Creoles (Fig. 9).

- At the Favard site, where the population is exclusively Amerindian, a low solar energy potential and a high rate of battery defects during the first years of operation did not bring about rejection of the technology, but did create an unsatisfactory relationship with the installer. We observed that all forms of obligation (agreements, payment) were rejected (Fig. 9). 
- At the Apatou site, where the population is exclusively of Maroon origin, a high energy potential available during the first years of operation certainly attracted and convinced users of the need to have electrical energy. However, insufficient maintenance, the presence of operating defects, and deterioration of system performance brought about an even stronger rejection of the technology as well as an unsatisfactory relationship with the installer (Figs. 9 and 10). There appears to be a strong misunderstanding concerning the agreements signed and the terms of payment.

- We observed that the users at the Mana/St. Laurent site, who were mainly of European origin, were those who best willingly accept the technology and its constraints, but do not view the need to have electrical energy as essential, contrary to the other sites. They have a good relationship with the installation company (Fig. 10)

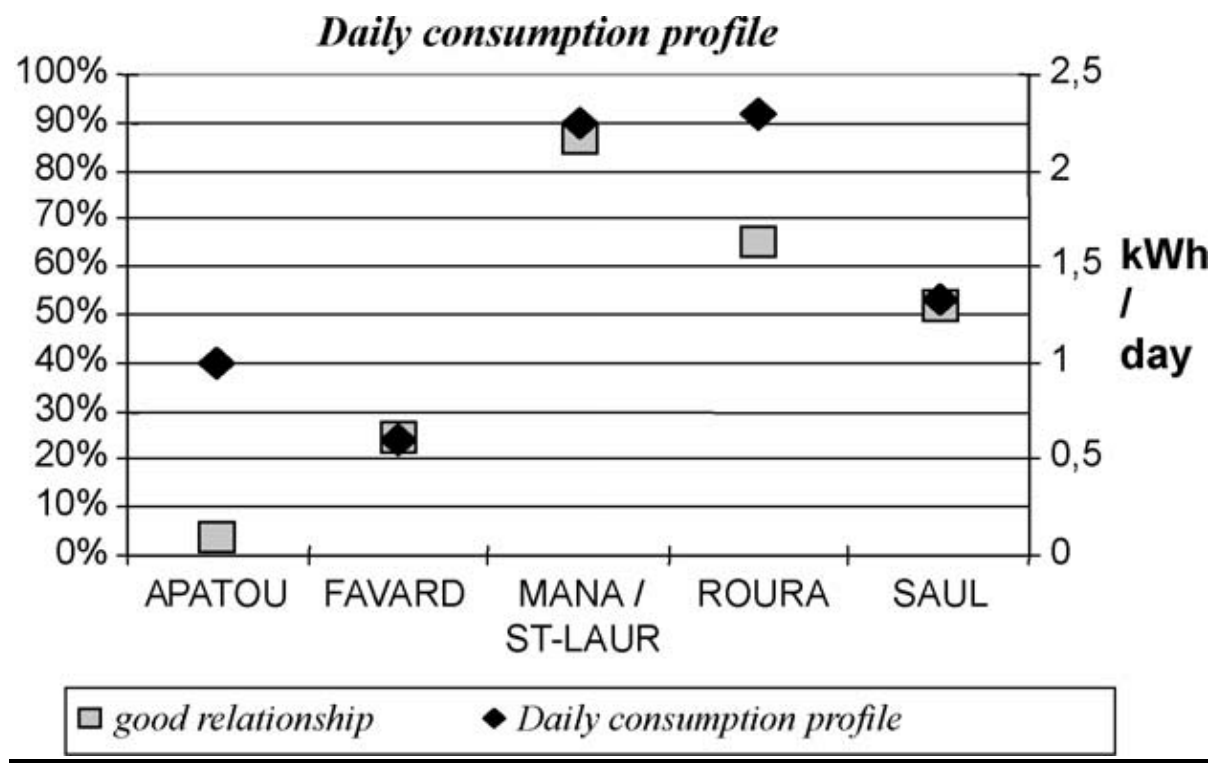

Fig. 10.Correlation between relationship quality with $P V$ installers and daily consumption profile

Several complementary analyses can been carried out using the data collected and presented in this report. Daily television use is significant. Television is the main source of entertainment and «standby » mode is the first choice of the persons questioned when they are not watching television. Moreover, we observed a certain confusion between standby mode and operation of the appliances. Certain clients thought that, during standby, the appliance was turned off, while others thought that refrigerators and freezers did not run continuously but that they remained in standby mode. It seems necessary to provide information on these different concepts. In this discussion, we concentrated on answering the questions raised at the beginning of the report.

What factors can lead to rejection of the system ? Several factors were revealed. First of all, dissatisfaction due to insufficient available electrical energy. This insufficiency appears to have different origins: 
- Low solar energy potential that the installation does not manage to exploit in order to satisfy user needs, or a high defect rate concerning battery voltage (maybe due to intensive use?)

- The attitude of the installation company appears to be considered as a factor in the rejection of the technology. Users complained of the lack of a relationship, insufficient contact, and the absence of on-site presence, which were felt to indicate an attitude of contempt on the part of the company. This attitude led to deterioration of the installations (Fig. 10).

- Generally speaking, users acknowledged that they hadn't understood the agreements and what their implication in the system was supposed to be. The users' relationship to the system should not be confused with their relationship to the installer. For example, the users in Saül who received training on the use of the system all said that they hadn't understood the agreements signed with the installer, and their relationship with the latter is quite unsatisfactory.

- The obligation to pay are factors which lead to conflict and deterioration of the relationship between users and the installation company

We would like to point out that particular attention should be paid to the potential solar energy available at a site and the dimensioning of the installations. The study appears to indicate that a slightly insufficient energy potential can lead to much lower productivity than that which could have been expected. Unless there is another explanation which could elucidate this phenomenon, it would appear that photovoltaic systems degrade low-level quantities of solar energy excessively (generating a yield which is proportionately lower).

What factors can incite users to cooperate?

We observed a strong attachment to the service provided by the photovoltaic system (except in Saiul), the only positive point the study highlighted. This is a sign that allows us to conclude that trust in the technology and the company that installed it can be re-established. In order for this to happen, each population's modes of relating would have to be taken into account very carefully and true personal contact re-established. The most important concern should not be profit or economic equilibrium but the initial objective intended for the photovoltaic installations: supplying energy in isolated areas. By what means can users be incited to become more involved in operating the system ? The possibility for users to get in touch with the installer appears to be a priority expectation. The users have many questions about the system and routine maintenance. They need to be listened to and reassured, especially when the availability of electrical energy is considered vital. What type of maintenance program would be the most adapted? What type of training should be planned for? The questions asked by the users during the interviews indicate that priority should be given to battery maintenance. The first training program to carry out should be on battery maintenance (adding water, acid, cleaning corroded terminals, measuring voltage, $\mathrm{pH}$, etc.) It is this element of the photovoltaic system which appears to be the main cause of failures. The 
maintenance program to adopt should be a joint approach involving one or several users at the different sites and the installation company's technicians.

\section{Conclusion and recommandations}

The study on photovoltaic system productivity in an Amazonian environment carried out on the socio-anthropological and technical levels has yielded a large amount of information and a wealth of results. A total of 91 homes equipped with photovoltaic systems were visited at different sites having different meteorological conditions. All these homes were off the EDF electricity grid. The relative distance from transportation routes was different and specific to each site: Certain sites can only be reached by air, others only by river, and still others can be reached by road. We deliberately chose clients belonging to different cultural groups. Therefore, the study includes clients of Amerindian, Maroon, Creole, and European origin. The first conclusion that can be drawn from the study is that introducing new technologies into populations with different socio-cultural backgrounds produces specific responses that should be taken into account very early on; care should be taken not to neglect them in order to avoid rejection of the technology and its players. Generally speaking, client perception of the photovoltaic system is mixed. They consider several aspects of the technology to be ecological (it is silent, natural, and linked to sunshine) and they willingly use the electrical energy generated, which most consider indispensable. However, the major drawbacks highlighted by the clients are the low capacity of the batteries, the poor performance of the system during rainy weather, and the lack of system maintenance. Still, the majority of them would not be prepared to break their contract with the installation company. The main concerns involve the disfunctioning of the photovoltaic system. On this point, the clients in Apatou and Favard consider that they do not get any attention from the installation company and they would like more visits and more contact. System failures (meteorology, breakdowns), coupled with incorrect use of electrical appliances by the clients, exacerbate the dissatisfaction experienced.

This study shows that the issue of energy in truly isolated areas (not reachable or very difficult to reach by road) is considered vital by the populations who live in these areas and who do not have other similar-strength energy sources available to them (Apatou, Favard). It appears that heavy economic constraints combined with differing cultural approaches may hampered the proper productivity of the photovoltaic installations present at these sites. 


\section{References}

[1] Tsoutsos T., Frantzeskaki N., Gekas V.,Environmental impacts from the solar energy technologies, Elsevier 2003, Energy Policy

[2] Gaunt C.T., Meeting electrification's social objectives in South Africa, and implications for developing countries, Elsevier 2004, Energy Policy

[3] Chakrabarti S., Subhendu C.

Rural electrification programme with solar energy in remote region-a case study in an island, Elsevier , Energy Policy 30 (2002) 33-42

[4] Ketlogetswe C, Mothudi TH. Solar home systems in Botswana-opportunities and constraints, Elsevier. Renewable and Sustainable Energy Reviews 2008 